\author{
Marquette University \\ e-Publications@Marquette
}

School of Dentistry Faculty Research and

Publications

Dentistry, School of

$12-2020$

\title{
Graphite/Gold Nanoparticles Electrode for Direct Protein Attachment: Characterization and Gas Sensing Application
}

\author{
Javad Shabani Shayeh \\ Shahid Beheshti University \\ Yahya Sefidbakht \\ Shahid Beheshti University \\ Meisam Omidi \\ Marquette University \\ Fatemeh Yazdian \\ University of Tehran \\ Lobat Tayebi \\ Marquette University, lobat.tayebi@marquette.edu
}

Follow this and additional works at: https://epublications.marquette.edu/dentistry_fac

Part of the Dentistry Commons

\section{Recommended Citation}

Shayeh, Javad Shabani; Sefidbakht, Yahya; Omidi, Meisam; Yazdian, Fatemeh; and Tayebi, Lobat, "Graphite/Gold Nanoparticles Electrode for Direct Protein Attachment: Characterization and Gas Sensing Application" (2020). School of Dentistry Faculty Research and Publications. 452.

https://epublications.marquette.edu/dentistry_fac/452 
Marquette University

e-Publications@Marquette

\section{Dentistry Faculty Research and Publications/School of Dentistry}

This paper is NOT THE PUBLISHED VERSION.

Access the published version via the link in the citation below.

Environmental Science and Pollution Research, Vol. 27, No. 34 (December 2020): 43202-43211. DOI. This article is (C) Springer and permission has been granted for this version to appear in ePublications@Marquette. Springer does not grant permission for this article to be further copied/distributed or hosted elsewhere without the express permission from Springer.

\section{Graphite/Gold Nanoparticles Electrode for Direct Protein Attachment: Characterization and Gas Sensing Application}

Javad Shabani Shayeh

Protein Research Center, Shahid Beheshti University, G. C., Velenjak, Tehran, Iran Yahya Sefidbakht

Protein Research Center, Shahid Beheshti University, G. C., Velenjak, Tehran, Iran Meisam Omidi

Protein Research Center, Shahid Beheshti University, G. C., Velenjak, Tehran, Iran Fatemeh Yazdian

Faculty of New Science and Technology, University of Tehran, Tehran, Iran Lobat Tayebi

Department of Developmental Sciences, Marquette University School of Dentistry, Milwaukee, WI, 53233, USA

Department of Engineering Science, University of Oxford, Oxford, OX1 3PJ, UK 


\section{Abstract}

In this work, graphite/gold nanoparticles (G/AuNPs) were synthesized through a facile chemical method, and its potential application for direct protein attachment for electrochemical detection of carbon monoxide (CO) was investigated. The preparation of G/AuNPs electrodes was optimized by synthesizing the nanoparticles in different concentration of $\mathrm{HAuCl}_{4} .3 \mathrm{H}_{2} \mathrm{O}$ at various temperatures. The G/AuNPs electrode was subsequently modified by four types of mercaptopropionic acid, including 1mercaptopropionic, 3-mercaptopropionic, 6-mercaptopropionic, and 11-mercaptopropionic acid, to achieve the best structure for protein attachment. Visible absorption and electrochemical studies showed that 3-mercaptopropionic acid possesses the best performance regarding the electrical conductivity between electrode and protein redox center. The cyclic voltammetry results revealed that the modified electrode has an appropriate performance for $\mathrm{CO}$ detection at very low concentrations while keeping a linear response. The limit of detection for the modified electrode was calculated to be about $0.2 \mathrm{ppb}$. Finally, the interactions of cytochrome $\mathrm{C}$ and carbon monoxides were simulated using molecular dynamics (MD), and the effect of protein conformation changes on the electrochemical signal was thoroughly examined. The simulation results suggested that the proposed electrochemical sensor has an acceptable performance for the detection of $\mathrm{CO}$ due to less fluctuation of amino acids near the protein chain in the presence of CO molecules.

\section{Keywords}

Graphite electrode, Au nanoparticles, Cytochrome C, Carbon monoxide, Electrochemical biosensor, Molecular dynamics

\section{Introduction}

$\mathrm{CO}$ is a hazardous material that has many threats for human beings, even in low concentrations. For instance, exposure to CO may result in the reduction of oxygen carrying in blood (Kakaei [18]; Mofenson et al. [25]). Inhaling CO at the concentration of $9 \mathrm{ppm}$ for $8 \mathrm{~h}$ or $25 \mathrm{ppm}$ for an hour is fatal (Weaver [46]). Therefore, fast and facile detection of $\mathrm{CO}$ at low concentrations is very imperative (Dolan [ 9]). Up to now, many efforts have been devoted to develop sensors for detection of CO through various techniques such as optical (Zayasu et al. [48]), electrical (Savage et al. [37]), biological (Blyth et al. [6]), and electrochemical sensors (Okamoto et al. [29]). Biosensors have attracted much more attention due to high specificity, selectivity, and sensitivity. Among the conventional biomarkers for the detection of $\mathrm{CO}$, proteins and enzymes are widely used for CO monitoring (Dürr et al. [10]; Omidi et al. [31]; Topoglidis et al. [44]; Topoglidis et al. [43]).

Proposing new types of enzyme-based electrode for recognizing substances in the gaseous phase has been the subject of importance in multiple studies. Kuretake et al. showed that immobilized enzymes on chromatography paper could be used as electrochemical gas biosensors (Kuretake et al. [22]). Cytochrome c (Cyt c) is known as one of the most common proteins which can be used for the detection of $\mathrm{CO}$ owing to its redox nature in electrochemical biosensors (Omidi et al. [32]). It is showed that how structural properties of Cyt c could affect the UV-Vis spectra upon reactivity with CO, NO, and $\mathrm{O}_{2}$ providing a basis for understanding the gas binding to the heme-based sensor proteins (Hough and Andrew [15]). The main mechanism in $\mathrm{CO}$ detection is attributed to the reduction of Cyt c by CO molecules, which decreases the number of oxidative site in protein (Omidi et al. [30]). On the other 
hand, one of the important points to fabricate a biosensor electrode is the modification of electrode surface that affects the performance of biosensor (Kakaei et al. [21]). Preparing a suitable platform for decoration of nanomaterials or self-assembly of them is the first step in fabricating an electrode (Ehsani et al. [12]; Mojtaba et al. [26]). In addition, the surface treatments of electrodes such as heat or chemical treatments have been widely considered as another modification method to improve the performance of electrodes (Kakaei and Gharibi [19]). Among the conventional methods of surface treatments, chemical treatment is dominant due to facile procedure and unsophisticated equipment (Kakaei et al. [20]). The immobilization of Cyt c on the electrode surface is also significant for the detection of $\mathrm{CO}$. For this purpose, linkers are usually employed for direct connection between Cyt c redox center and the electrode surface in order to facilitate the rate of electron transfer. Atomic structures play an important role on the electrical behavior of linkers (Saito et al. [35]). Various characteristics such as length, chemical nature, and type of conjugation are the main factors that might influence the conductivity of linkers (Odom et al. [28]). The electrochemical activity of Cyt c should be stable during the attachment process in order to preserve the electrical conductivity between the electrode and protein active sites. Using nanoparticles such as $\mathrm{Au}, \mathrm{Ag}$, and carbon nanostructures can maintain the electrical conductivity between biomarkers and electrode (Ehsani et al. [11]; Eshlaghi et al. [13]). Mercaptopropionic acid (MPA) is an organic acid that can be used for the attachment of Cyt c on the surface of gold electrodes. The carboxylic acid groups on MPA can react with Cyt c through covalent interaction. On the other side, Au nanoparticles can be attached on the surface through thiolation due to the presence of thiol groups. Thus, the modified electrode with Au nanoparticles significantly improves the electron transfer and sensitivity of Cyt c for the detection of CO (Aggarwal et al. [ 3]; Cedervall et al. [ 8]; Lacerda et al. [23]).

Investigating the possible interactions between $\mathrm{CO}$ and $\mathrm{Cyt} \mathrm{c}$ has a pivotal role for designing and fabricating more applicable biosensor for $\mathrm{CO}$ detection. Although there are many reports on the detection of $\mathrm{CO}$ molecule, considering the possible interactions between this molecule and Cyt c has been ignored. Indeed, the effect of $\mathrm{CO}$ on unfolding or aggregation of Cyt c complex is not obvious until now. Thermodynamic properties, kinetics of protein folding, and protein structure are three major factors which profoundly affect the unfolding of Cyt c. In this work, a facile and novel procedure for the synthesis of G/AuNPs electrode was developed. The as-prepared electrode was then modified with Cyt c for high accurate detection of CO molecules. Furthermore, the role of MPA as a linker was thoroughly studied and optimized. Finally, the molecular interaction between Cyt c and CO molecules was simulated through MD simulation.

\section{Material and methods}

Instruments and materials

All the chemical materials purchased from Merck and used without further purification and manipulation. Double distilled water was used throughout the experiments. Horse heart cytochrome c (molecular weights $12,384 \mathrm{~g} / \mathrm{mol}$ ) was purchased from Sigma and qualified through UV-Vis absorption at $550 \mathrm{~nm}$ (Abass et al. [ 1]; Wang and Wang [45]). All electrochemical measurements were carried out in phosphate buffer solution $\mathrm{pH}=7.4$ at room temperature using a galvano/potentiostat (IVIUMSTAT vertex). A conventional three-electrode electrochemical cell containing an $\mathrm{Ag} / \mathrm{AgCl}$ as a reference electrode (Argental, $3 \mathrm{M} \mathrm{KCl}$ ) and a platinum wire (diameter $0.5 \mathrm{~mm}$ ) as the counter electrode was 
used for all measurements. Hi-polymer graphite pencil B6 black leads ( $2 \mathrm{~mm}$ ) were obtained from Cretacolor Totiens $\mathrm{Co}$ and utilized as the working electrode. Electrical contact with the lead was provided by soldering copper wire to the metallic parts which fixed the lead inside a pipette tip. The far-UV circular dichroism (CD) spectroscopy was obtained by an Aviv model 215 spectropolarimeter to give the content of the regular secondary structure. The UV-Vis spectra were measured by 2550 Shimadzu, Japan.

\section{Molecular dynamic simulation}

Energy minimization and molecular dynamics simulations were performed by GROMACS (5.1.4) and GROMOS53 (Abraham et al. [ 2]; Oostenbrink et al. [33]). The water box was created with at least $10 \AA$ distances from protein using 10829 SPC water molecules and applying periodic boundary conditions. The 20 and 200 molecules of carbon monoxide were randomly introduced to the simulation box replacing with water molecules. The B3LYP/6-31G* carbon monoxide optimized geometry and parameters were obtained from automatic topology builder (ATB) (Malde et al. [24]).

Considering the protein net charge system, neutralization was conducted by adding 7 chloride anions. The system was subjected to 5000 steps of energy minimization to relax the structure and equilibrate the solvent around the protein while keeping at a constant temperature of $300 \mathrm{~K}$ (NVT) simulation. Afterward, NPT optimization was performed for 500 ps. In order to increase the likelihood of achieving the appropriate structure, the MD simulation was performed for $1000 \mathrm{ps}$. GROMACS implemented tools were carried out for trajectory analysis. Using least-squares fitting the root-mean-square deviation (RMSD) and root mean square fluctuation (RMSF) were calculated for the protein backbone (Bitaab et al. [ 5]; Sefidbakht et al. [39]). The radius of gyration for cytochrome $c$ and cytochrome in the presence of carbon monoxide was calculated. Finally, DSSP (hydrogen bond estimation algorithm) $\mathrm{V}$ 2.1.0 was employed to compare the probable alteration in the secondary structure of cytochrome c for both cases during MD (Joosten et al. [17]).

\section{Preparation of graphite oxide and G/AuNPs electrode}

Graphite oxide was synthesized according to the previously reported Hummer method (Hummers Jr and Offeman [16]). At the first step, graphite electrodes were immersed in $\mathrm{HNO}_{3} / \mathrm{H}_{2} \mathrm{SO}_{4}(1: 1)$ solution at room temperature in bath sonication for $2 \mathrm{~h}$. After that, the electrodes were rinsed and placed in 10 $\mathrm{ml}$ of a solution containing $0.1 \mathrm{M} \mathrm{HAuCl}_{4}$ and $40 \mathrm{mg} \mathrm{NaBH} 4$ at $50{ }^{\circ} \mathrm{C}$ for various period of time including $30,60,90$, and $120 \mathrm{~min}$ as G/Au1, G/Au2, G/Au3, and G/Au4, respectively.

\section{Preparation of working electrode}

In order to optimize the composition and concentration of MPA, four G/Au NPs electrodes were prepared and immersed in solutions containing 1-mercaptopropionic acid (1-MPA), 3mercaptopropionic acid (3-MPA), 6-mercaptopropionic acid (6-MPA), and 11-mercaptopropionic acid (11-MPA). The concentration of MPA solutions in this step kept constant about $0.02 \mathrm{M}$, and the electrodes were immersed for $2 \mathrm{~h}$ at room temperature. Next, the electrodes were rinsed by water to remove excess physically adsorbed compounds. Finally, the modified electrodes were incubated at $4{ }^{\circ} \mathrm{C}$ in Cyt c solution in the presence of 1-[3-(dimethylamino) propyl]-3-ethylcarbodiimide/ $\mathrm{N}$ hydroxysuccinimide (EDC/NHS) with the concentration of $0.08 \mathrm{M}$ and $0.1 \mathrm{M}$, respectively. The 
substrate was then thoroughly rinsed with deionized water to remove the weakly adsorbed Cyt c (Canterford [ 7]).

\section{CO calibration solution}

The saturated solution of $\mathrm{CO}$ with an approximate concentration of $0.98 \mathrm{mM}$ was prepared at $25^{\circ} \mathrm{C}$ through bubbling $\mathrm{CO}$ gas in $5 \mathrm{ml}$ of PBS ( $\mathrm{pH}$ 7) for $1 \mathrm{~h}$. To avoid the dispersion of $\mathrm{CO}$, all the measurements were performed in sealed cell. The detection of $\mathrm{CO}$ was carried out in different time periods including $10,20,30,40$, and $50 \mathrm{~s}$; considering that the operation is time-consuming, the time $30 \mathrm{~s}$ was selected for further studies. The results showed that the electrode has the best electrochemical performance after the passage of $30 \mathrm{~s}$.

\section{Result and discussions}

Figure 1 shows the step-by-step procedure for the preparation of the working electrode. As illustrated, the first step is attributed to the deposition of Au nanoparticles on the surface of the electrode. For this purpose, the surface was initially modified with oxygen containing functional groups to increase the probability of AuNPs attachment. The FTIR spectra of the treated graphite electrodes with $\mathrm{HNO}_{3} / \mathrm{H}_{2} \mathrm{SO}_{4}$ (1:1) at various times are shown in Fig. 2. As can be seen, the majority of created functional groups on the surface of the electrode alters from hydroxyl to epoxy by the passage of time. The sharp peaks at around 3400 and $1700 \mathrm{~cm}^{-1}$ are attributed to hydroxyl and carboxyl groups, respectively. The distinctive peaks about 1600,1400 , and $1050 \mathrm{~cm}^{-1}$ are related to the formation of carboxylic and epoxy groups on the surface of electrode, respectively. According to the FTIR spectra, it seems that the optimum time for acid treatment of electrodes is $90 \mathrm{~min}$.
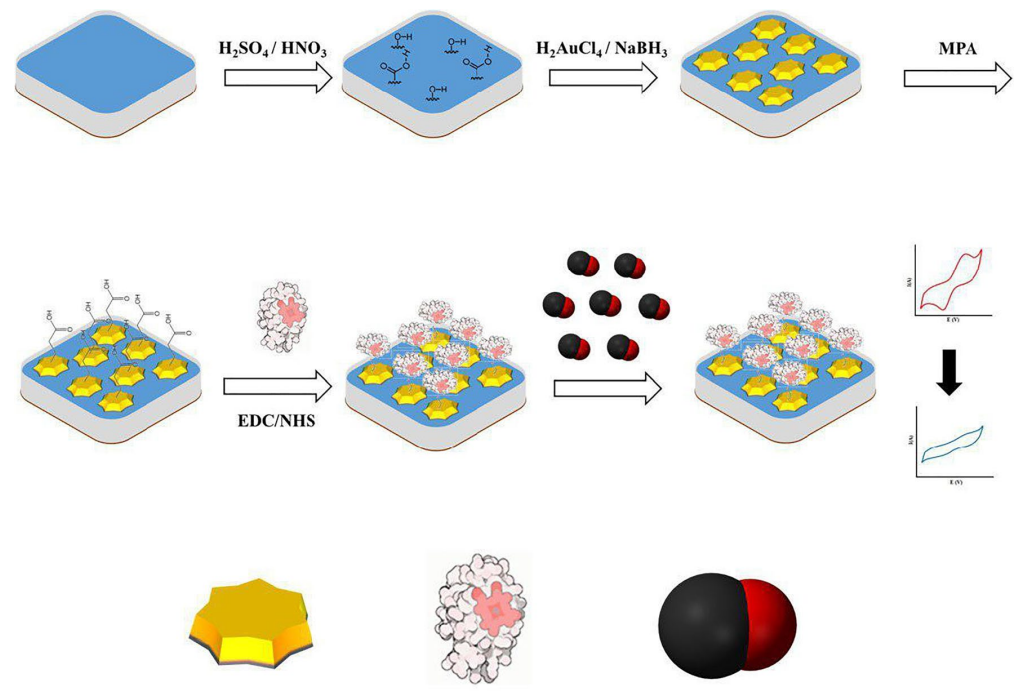

Gold Nanoparticle

Cytochrome $c$

Carbon Monoxide

Fig. 1 Schematic illustration for the preparation of the working electrode 


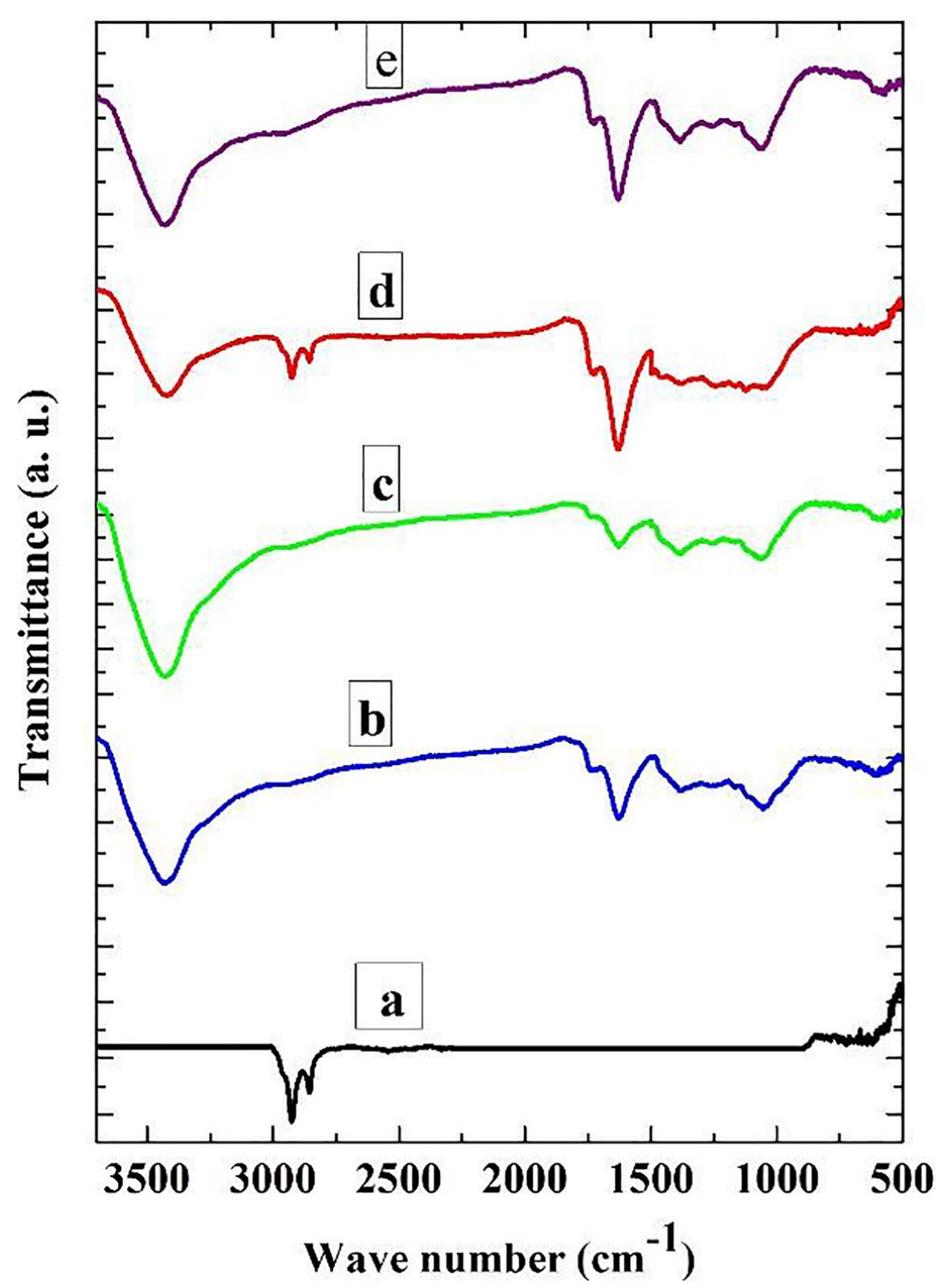

Fig. 2 FTIR spectra of graphite bare electrode (a) and acid treated at 30 (b), 60 (c), 90 (d), and 120 min (e)

The XRD patterns of the electrodes are shown in Fig. 3. As illustrated, the sharp peak at $2 \theta^{\sim} 25^{\circ}$ is ascribed to the (002) plane of graphite without any further diffraction characteristic of graphite. The XRD pattern of $\mathrm{GO}$ demonstrates that the distinctive peak at $2 \theta^{\sim} 25^{\circ}$ diminished and the sharp peak at $2 \theta^{\sim} 11^{\circ}$ appears corresponding to the formation of GO on the surface of the electrode (Salehifar et al. [36]). The small and broad peak observed at about $2 \theta^{\sim} 24^{\circ}$ can be associated with graphite, indicating the presence of small amounts of graphite. XRD diagram of G/AuNPs shows that the surface of the electrode was reduced and coated by Au NPs. The diffraction peaks at $2 \theta^{\sim} 38.5^{\circ}, 64.3^{\circ}$, and $77.6^{\circ}$ are attributed to (111), (220), and (311) planes of AuNPs, respectively. Furthermore, the additional peak at about $2 \theta^{\sim} 43.6^{\circ}$ is related to overlapping (200) reflection plane of $A u$ at $44^{\circ}$ with (100) plane of graphite match with JCPDS data card 04-0784 (Wolf and Xu [47]). Furthermore, using the Debye-Scherer equation, the mean size of AuNPs was calculated about $60 \mathrm{~nm}$. 


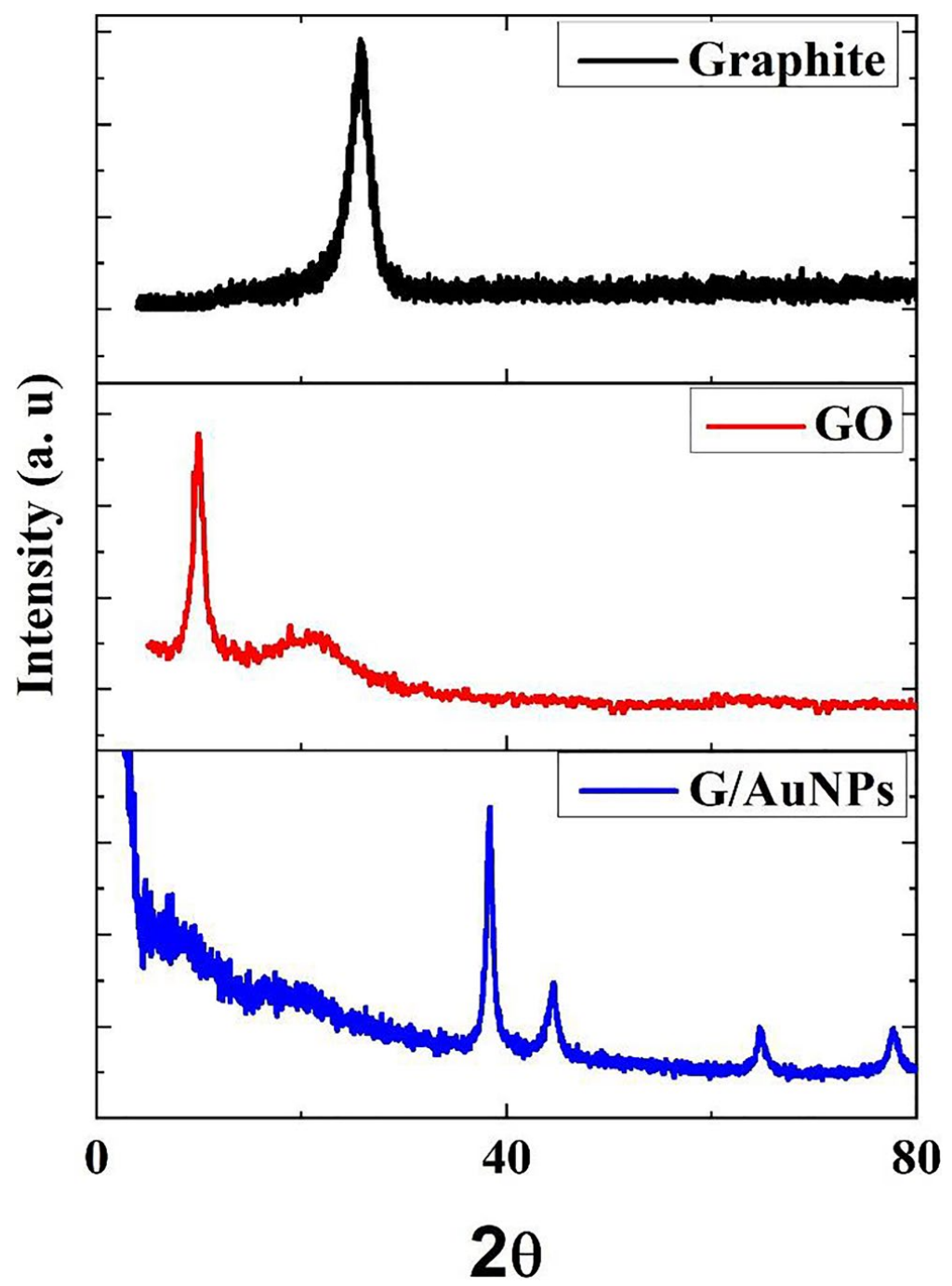

Fig. 3 XRD patterns of G, GO, and G/Au NPs electrodes

The SEM images of as-prepared electrodes are shown in Fig. 4. As can be seen, the density of Au NPs increases by enhancing the time of immersion in the boiling reaction cell. The SEM images indicate that the deposition of Au NPs on the graphite electrode reaches the optimum condition after being immersed for $90 \mathrm{~min}$ (Fig. 4d). After that, by increasing the concentration of $\mathrm{HAuCl}_{4} \cdot 3 \mathrm{H}_{2} \mathrm{O}$, a noticeable agglomeration of Au NPs has been occurred (Fig. 4e). The EDS results of the as-prepared electrodes are summarized in Table 1. As expected, the atomic percentage of Au nanoparticles increases by increasing the time of immersion in $\mathrm{HAuCl}_{4} \cdot 3 \mathrm{H}_{2} \mathrm{O}$ solution. Although $\mathrm{G} / \mathrm{Au} 4$ electrode has more content of $\mathrm{Au}$ NPs, the G/Au3 electrode was indicating the optimum electrochemical behavior. 


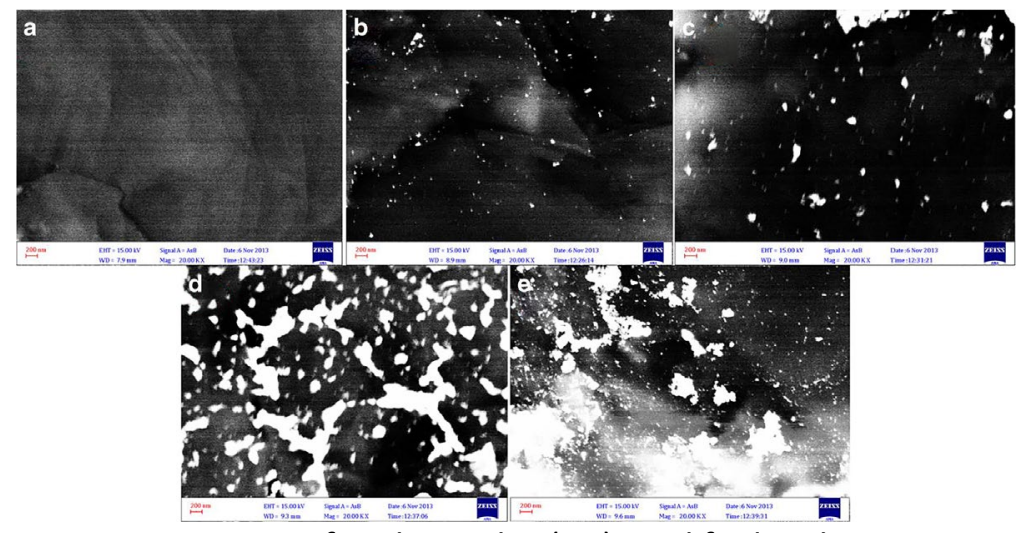

Fig. 4 SEM images of G electrodes (GE) modified with various amount of Au NPs, GE (a), G/Au 1 (b), G/Au 2 (c), $\mathrm{G} / \mathrm{Au} 3$ (d) and G/Au 4 (e)

Table 1. Quantitative results of EDS analysis for G/Au electrodes

\begin{tabular}{|l|l|l|}
\hline Electrode & Au wt\% & Carbon wt\% \\
\hline GE & 0 & 100 \\
\hline G/Au1 & 1.1 & 98.9 \\
\hline G/Au2 & 6.9 & 93.1 \\
\hline G/Au3 & 8.7 & 91.3 \\
\hline G/Au4 & 12.5 & 87.5 \\
\hline
\end{tabular}

Figure 5 demonstrates the FTIR-ATR spectra of modified G/AuNPs electrodes with different types of MPA. As seen, the strong absorbance peak at $1690 \mathrm{~cm}^{-1}$ is attributed to carboxylate groups (curve a). The appearance of distinctive peaks at 1557 and $1403 \mathrm{~cm}^{-1}$ is related to $\mathrm{C}-\mathrm{H}$ bending (curve $\mathrm{b}$ ). Increasing the number of $\mathrm{CH}_{2}$ bands in 3-MPA, 6-MPA, and 11-MPA leads to appearing the absorbance at 2845-2916 $\mathrm{cm}^{-1}$, which can be ascribed to $\mathrm{C}-\mathrm{C}$ bonds (curve $\mathrm{c}, \mathrm{d}$, and e). 


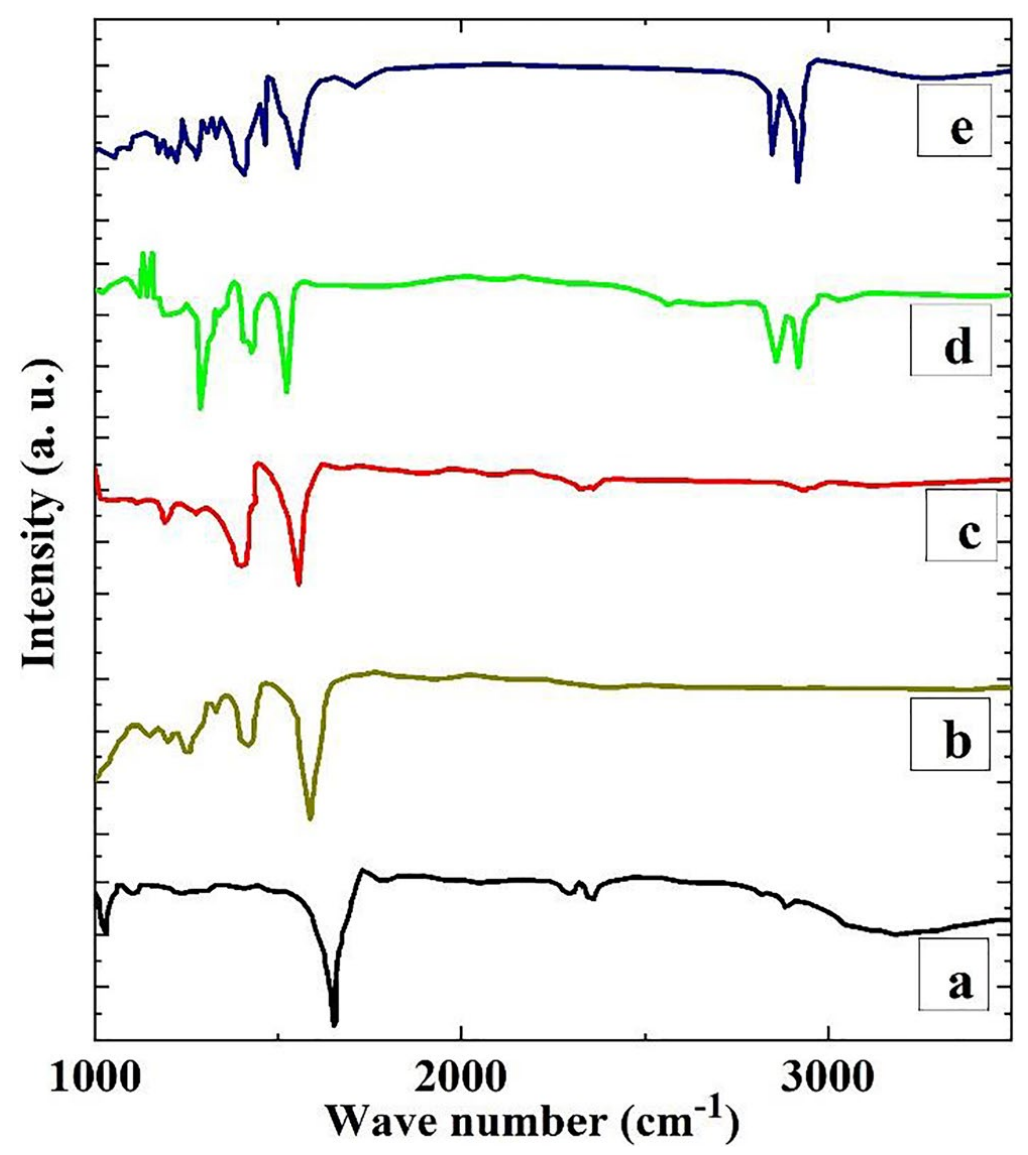

Fig. 5 FTIR-ATR diagrams of G/AuNPs electrode (a) modified by 1-MPA (b), 3-MPA (c), 6-MPA (d), and 11-MPA (e)

Figure 6 indicates the visible spectroscopy of G/AuNPs/Cyt c and modified electrodes by different types of MPA. Accordingly, the spectroscopy of G/AuNPs/Cyt c presents an absorbance peak at about 530 $\mathrm{nm}$, while the appearance of another absorbance peak at $400 \mathrm{~nm}$ after modifying the electrode with Cyt c implies the successful conjugation between the surface of the electrode and Cyt c. As illustrated, the maximum absorbance of Cyt c observed in the case of 3-MPA, indicating the highest electrical conductivity between Cyt c and 3-MPA, among other electrodes. Cyclic voltammetry is one of the useful techniques that can be used for the study of various electrodes (Shayeh et al. [40]). Figure 7 a presents the CV curves of bare and modified graphite electrodes. As can be seen, after the modification of electrode by AuNPs, due to increasing the conductivity and active surface area of the electrode, the magnitude of non-faradic behavior of the modified electrode increased. After MPA attachment, due to the non-conductive nature of MPA, the active surface area of the electrode diminished, and therefore, the magnitude of non-faradic behavior of the modified electrode decreased. 


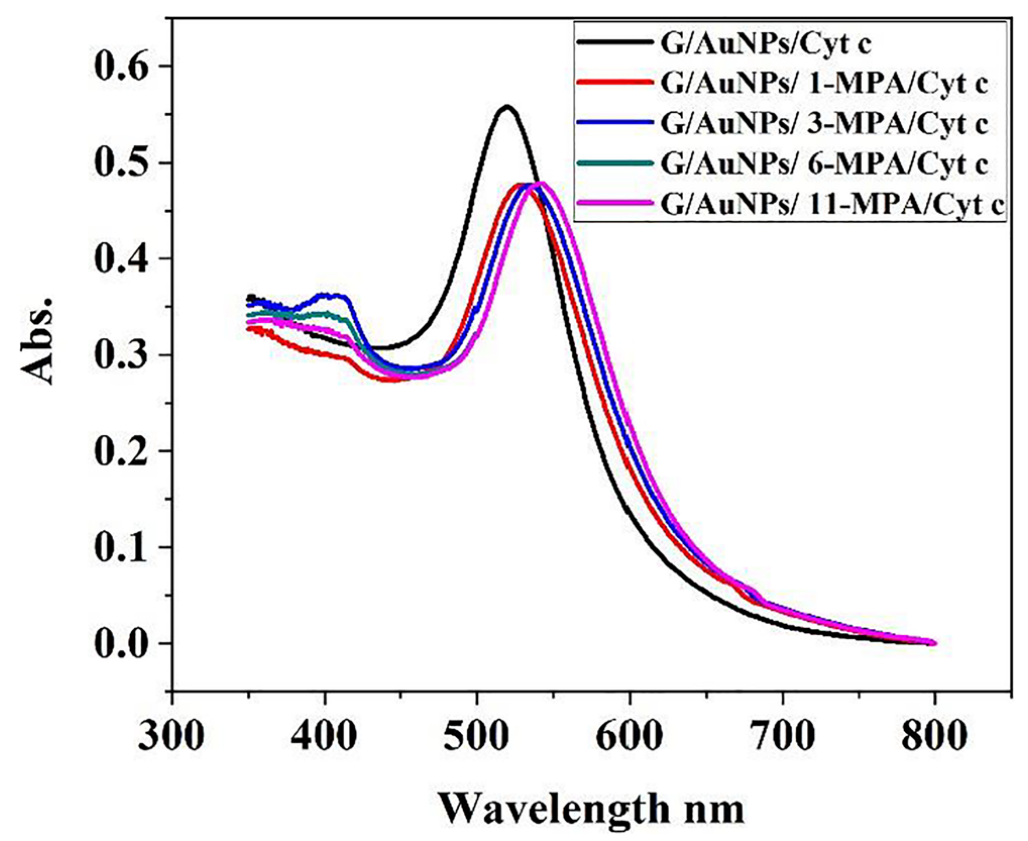

Fig. 6 Visible spectroscopy analysis of modified electrode by cytochrome c protein
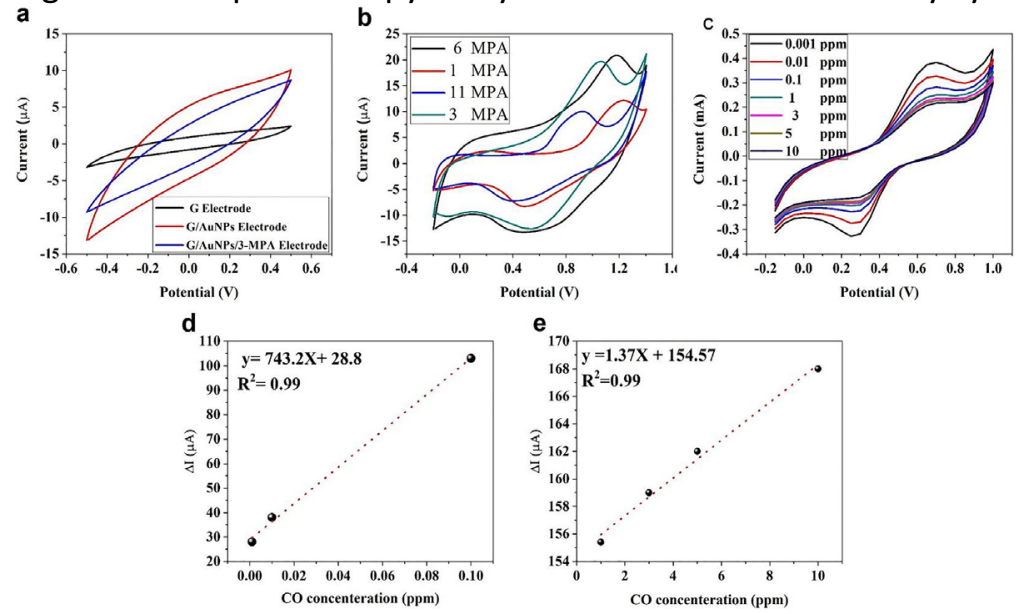

Fig. 7 CVs of graphite electrode modified with AuNPs and 3-MPA (a), CVs of G/AuNPs/MPA/Cc modified electrodes with various types of MPA connectors at the scan rate of $50 \mathrm{mV} / \mathrm{s}$ in $0.05 \mathrm{M} \mathrm{PBS}$ (b), CVs of G/AuNPs/3-MPA/Cyt c electrode at the scan rate of $50 \mathrm{mV} / \mathrm{s}$ in various $\mathrm{CO}$ concentrations (c), and calibration curves of relative currents of G/AuNPs/3-MPA/Cc electrode versus $\mathrm{CO}$ concentrations $(d, e)$

The second step in electrode preparation is to optimize the conjugation of Cyt c protein and electrode by using MPA. In this regard, four types of MPA were investigated, and the most conductive electrode was selected as the main working electrode for the detection of $\mathrm{CO}$ molecules. Figure $7 \mathrm{~b}$ shows the typical CVs of modified electrodes by various kinds of MPA. All the CV curves have a redox peak corresponding to oxidation and reduction of cytochrome $C$ protein. As observed, G/AuNPs/3-MPA/Cyt c electrode has the best electrochemical performance between all the electrodes due to the highest current density and lowest potential compared with the other electrodes. The pattern shows that $3-$ MPA can be connected to the active center of Cyt $\mathrm{c}$ to the surface of the electrode, and by increasing the length of MPA chains, the electrical conductivity between the electrode surface and Cyt c active center decreased. Therefore, G/AuNPs/3-MPA/Cyt c was selected as the optimized electrode for further characterization. 
According to Fig. 7c, decreasing the number of active sites on the surface of the electrode is due to the electrochemical reduction of Cyt c by $\mathrm{CO}$ molecules. Thus, the maximum current of redox peak decreases by increasing the concentration of $\mathrm{CO}$ owing to faster electrochemical reaction between Cyt $\mathrm{c}$ and $\mathrm{CO}$ molecules. Besides, at higher concentrations, the redox peak of Cyt c diminishes due to the consumption of all Cyt c proteins by $\mathrm{CO}$ molecules on the surface of the modified electrode. The proposed assembled electrode possesses an excellent linear behavior which is one of the most important features of the electrochemical biosensor (Baniasadi et al. [4]; Rashidi et al. [34]). Figure $7 \mathrm{~d}$ shows the relative peak currents of G/AuNPs/3-MPA/Cyt c electrode versus concentration of CO. At a lower concentration of $\mathrm{CO}$, the electrode shows a linear response implying high sensitivity of the assembled electrode for $\mathrm{CO}$ detection. However, at higher concentration of CO (1-10 ppm), a linear correlation ( $R=0.99$ ) between the value of relative currents and the concentration of CO indicates linear behavior of electrode even at high concentration (Fig. 7e). Therefore, the results show that G/AuNPs/3-MPA/Cc electrode can be used in a broad range of $\mathrm{CO}$ concentrations for the detection of $\mathrm{CO}$ molecules. The limit of detection (LOD) was also calculated to be about $0.2 \mathrm{ppb}$ with S/N ratio of 3 . It should be noted that the required time for CO detection was optimized. The UV-Vis spectra were also used to investigate the effect of $\mathrm{CO}$ molecules on Cyt c protein at room temperature (Farivar et al. [14]; Sefidbakht et al. [38]). According to Fig. 8a, the UV-Vis spectra of Cyt c in the presence of $1 \%$ CO shows four absorptions bands at different wavelengths. The distinctive peaks at around 280,350 , and $410 \mathrm{~nm}$ are ascribed to the aromatic amino acid region. The broad band at around $530 \mathrm{~nm}$, which can be observed in both spectra, is related to oxidized protein; however, the characteristic peak near 550 $\mathrm{nm}$ can be attributed to the presence of CO molecules, which leads to the reduction of Cyt c (MoosaviMovahedi et al. [27]). Hence, it can be well inferred that the reduction of Cyt c by CO can be the main reason of structural deformation. Figure $8 \mathrm{~b}$ shows the UV-CD spectra of bare Cyt $c$ and in the presence of $\mathrm{CO}$ molecules. As presented, Cyt c in the presence or absence of $\mathrm{CO}$ molecules has a negative peak around $210 \mathrm{~nm}$ suggesting the presence of high alpha-helical structures in both cases. However, the more negative pick of Cyt $\mathrm{c}$ in the presence of $\mathrm{CO}$ molecules confirms the creation of higher alpha helical structure after the addition of $\mathrm{CO}$. Thus, the circular dichroism data confirms the more order in the secondary structure of Cyt $\mathrm{c}$ in the presence of carbon monoxide.
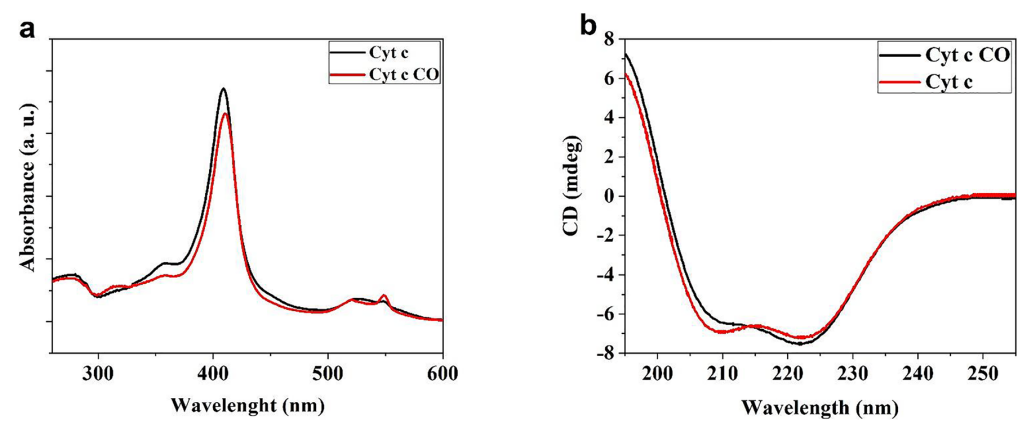

Fig. 8 a UV-Vis spectra of $1.25 \mathrm{mg} / \mathrm{ml}$ cytochrome $\mathrm{c}$ and cytochrome $\mathrm{c}$ in the presence of carbon monoxide of $1 \%$ at $25^{\circ} \mathrm{C}$. b UV-CD spectra recorded for cytochrome $\mathrm{c}$ and cytochrome $\mathrm{c}(\mathrm{red})$ in the presence of carbon monoxide (blue). The corresponding silver nanoparticle-AChE system at the PB concentration of $0.20 \mathrm{mg} / \mathrm{ml}(\mathrm{pH} 7.4,25$ $\mathrm{mM}$ ) and carbon monoxide concentrations of $1 \%$ at $25^{\circ} \mathrm{C}$

These observations were further investigated and approved through molecular dynamic simulations. Figure 8 shows the RMSD of Cyt $c$ in the water and the presence of 20 and 200 molecules of carbon 
monoxide. The presence of CO generally reduces the RMSD changes during the MD. The radius of gyration $\left(R_{g}\right)$ over trajectory was also observed to be deviating between 1.32 and $1.36 \mathrm{~nm}$. Although the presence of carbon monoxide shows some variations in $\mathrm{R}_{\mathrm{g}}$, these effects are nearly converged after 900 ps of simulation. The molecular dynamics study of this electron transfer protein adsorption to a gold surface has shown no unfolding tendency in the secondary structure. In the real system, these particular structural changes observed here might somehow occur differently as it is investigated for heme reduction in redox proteins experimentally (Soares et al. [42]). However, it can be inferred that the flexibility of the portion of the Cyt c might affect the electron transfer rate (Siwko and Corni [41]). The RMSF is representative of the amino acids movement during the simulation (Fig. 9). These flexibilities in dynamics seem to be related to the gas concentration as can be understood from RMSF an RMSD plots represented here. As it can be well inferred, the fluctuation of various amino acids along the protein chain is reduced in the presence of carbon monoxide. Using DSSP, it would be possible to follow changes in the secondary structure content of protein from the trajectory. At the first glance, Fig. 10 represents that the Cyt c possesses five distinguished alpha helix regions (i.e., residues 4-14, 51-55, 62-70, 72-75, and 89-102). It seems that in the presence of carbon monoxide, the structural elements are more clearly formed especially in the fourth helix residues $72-75$. This observation is in good agreement with experimental studies presented before.

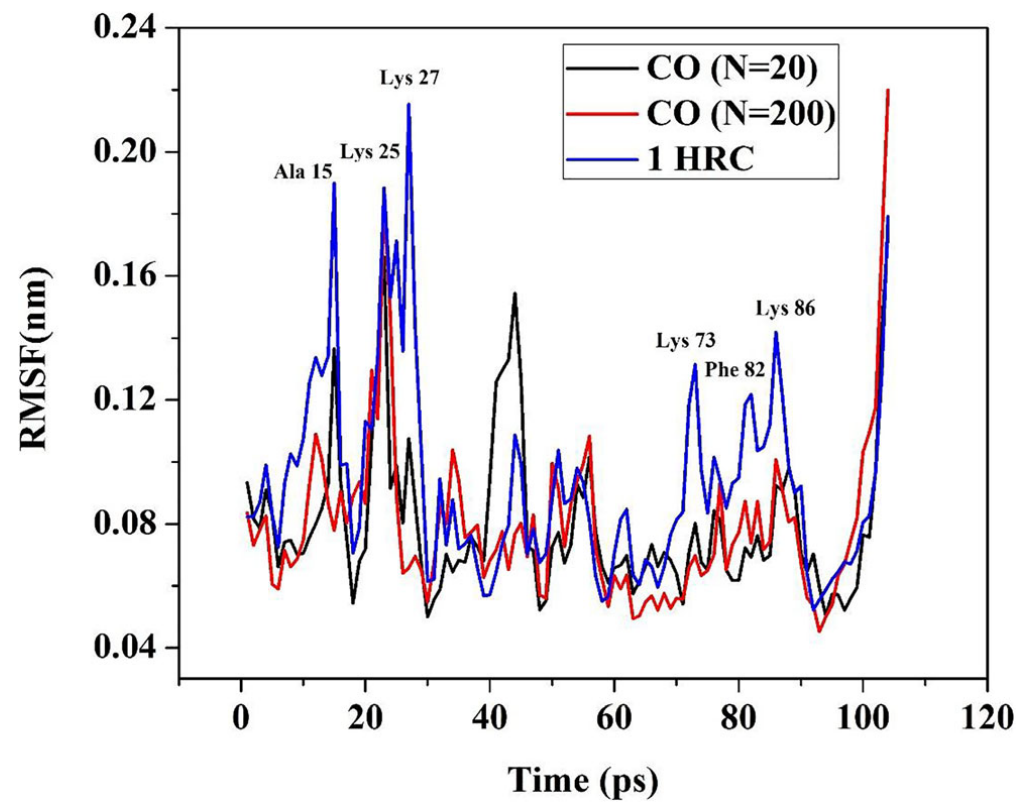

Fig. 9 The average RMSF value obtained from trajectory MD for the model (AMY1) and template (6TAA)
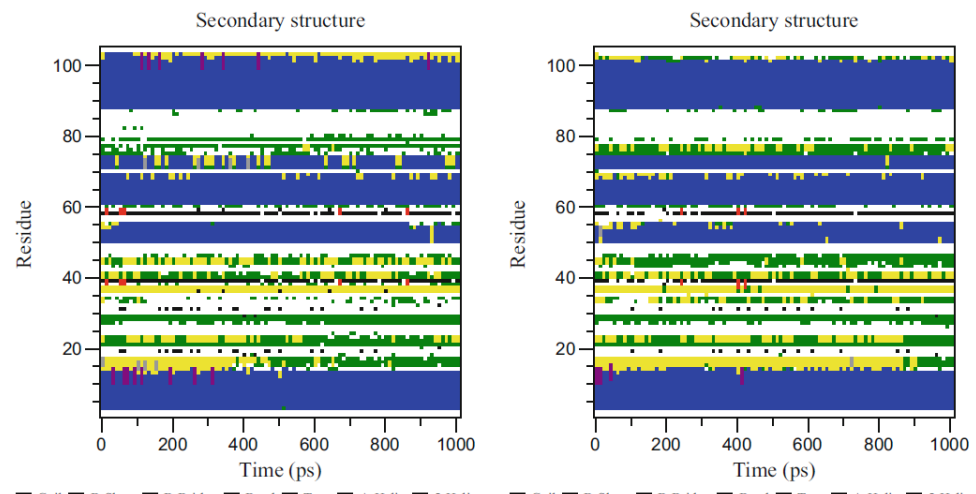
$\square$ Coil $\square$ B-Sheet $\square$ B-Bridge $\square$ Bend $\square$ Tum

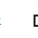


Fig. 10 The change in secondary structure over simulation for $1 \mathrm{HRC}$ in water and in the presence of carbon monoxide

It should be mentioned that the major effector in the electron transfer rate is related to the geometrical distance from the heme group in the active site and the electrode. However, the slight changes in the tertiary structure of heme proteins and its effect on the electron transfer are subject of study to advance the heme-based protein biosensors.

\section{Conclusion}

In this work, graphite/gold nanoparticles were chemically synthesized through immersion of graphite electrode in boiling $\mathrm{HAuCl}_{4} .3 \mathrm{H}_{2} \mathrm{O}$ solution without any further procedure. The SEM images showed that Au NPs were uniformly dispersed on the surface of the graphite electrode, and the modified electrode is very suitable for protein attachment for electrochemical detection of $\mathrm{CO}$ molecules. The conjugation of Cyt $c$ on the surface of the modified electrode was optimized by using different types of MPA. The electrochemical and spectroscopy characterizations revealed that the proposed electrochemical-based sensor has a great potential application to for detection of $\mathrm{CO}$ molecules in both low and high concentrations via a tremendous linear response. Molecular dynamic results suggested that the interactions between Cyt $\mathrm{c}$ and $\mathrm{CO}$ might compact the 3D structure of Cyt $\mathrm{c}$, which enhances the availability of Cyt c structure for facile and rapid detection of $\mathrm{CO}$ molecules through an electrochemical reaction.

\section{Funding information}

The authors would like to declare that this investigation was supported by Shahid Beheshti University G.C., research grant. No. 600/1427.

\section{Publisher's note}

Springer Nature remains neutral with regard to jurisdictional claims in published maps and institutional affiliations.

\section{References}

Abass A, Hart J, Cowell D. Development of an amperometric sulfite biosensor based on sulfite oxidase with cytochrome c, as electron acceptor, and a screen-printed transducer. Sensors Actuators B Chem. 2000; 62: 148-153. 10.1016/S0925-4005(99)00385-8

Abraham MJ, Murtola T, Schulz R, Páll S, Smith JC, Hess B, Lindahl E. GROMACS: High performance molecular simulations through multi-level parallelism from laptops to supercomputers. SoftwareX. 2015; 1: 19-25. 10.1016/j.softx.2015.06.001

Aggarwal P, Hall JB, McLeland CB, Dobrovolskaia MA, McNeil SE. Nanoparticle interaction with plasma proteins as it relates to particle biodistribution, biocompatibility and therapeutic efficacy. Adv Drug Deliv Rev. 2009; 61: 428-437. 10.1016/j.addr.2009.03.009

Baniasadi L. An inhibitory enzyme electrode for hydrogen sulfide detection. Enzym Microb Technol. 2014; 63: 7-12. 10.1016/j.enzmictec.2014.04.016 
Bitaab M, Siadat SR, Pazooki J, Sefidbakht Y. Antibacterial and molecular dynamics study of the Dolabellanin B2 isolated from sea slug, Peronia peronii. Biosci Biotechnol Res Asia. 2015; 12: 2023-2035. 10.13005/bbra/1870

Blyth DJ, Aylott JW, Richardson DJ, Russell DA. Sol-gel encapsulation of metalloproteins for the development of optical biosensors for nitrogen monoxide and carbon monoxide. Analyst. 1995; 120: 2725-2730. 10.1039/AN9952002725

Canterford D. Simultaneous determination of cyanide and sulfide with rapid direct current polarography. Anal Chem. 1975; 47: 88-92. 10.1021/ac60351a046

Cedervall T. Understanding the nanoparticle-protein corona using methods to quantify exchange rates and affinities of proteins for nanoparticles. Proc Natl Acad Sci. 2007; 104: 2050-2055. $10.1073 /$ pnas.0608582104

Dolan MC. Carbon monoxide poisoning. Can Med Assoc J. 1985; 133: 392

Dürr M, Rosselli S, Yasuda A, Nelles G. Band-gap engineering of metal oxides for dye-sensitized solar cells. J Phys Chem B. 2006; 110: 21899-21902. 10.1021/jp063857c

Ehsani A, Parsimehr H, Nourmohammadi H, Safari R, Doostikhah S. Environment-friendly electrodes using biopolymer chitosan/poly ortho aminophenol with enhanced electrochemical behavior for use in energy storage devices. Polym Compos. 2019; 40: 4629-4637. 10.1002/pc.25330

Ehsani A, Bigdeloo M, Assefi F, Kiamehr M, Alizadeh R. Ternary nanocomposite of conductive polymer/chitosan biopolymer/metal organic framework: synthesis, characterization and electrochemical performance as effective electrode materials in pseudocapacitors. Inorg Chem Commun. 2020; 115: 107885. 10.1016/j.inoche.2020.107885

Eshlaghi MA, Kowsari E, Ehsani A, Akbari-Adergani B, Hekmati M. Functionalized graphene oxide GO[Imi-(CH2)2-NH2] as a high efficient material for electrochemical sensing of lead: synthesis surface and electrochemical characterization. J Electroanal Chem. 2020; 858: 113784. 10.1016/j.jelechem.2019.113784

Farivar F, Moosavi-Movahedi AA, Sefidbakht Y, Nazari K, Hong J, Sheibani N. Cytochrome c in sodium dodecyl sulfate reverse micelle nanocage: from a classic electron carrier protein to an artificial peroxidase enzyme. Biochem Eng J. 2010; 49: 89-94. 10.1016/j.bej.2009.11.016

Hough MA, Andrew CR (2015) Chapter one - cytochromes c': structure, reactivity and relevance to haem-based gas sensing. In: Poole RK (ed) Advances in Microbial Physiology, vol 67. Academic Press, pp 1-84. 10.1016/bs.ampbs.2015.08.001

Hummers WS Jr, Offeman RE. Preparation of graphitic oxide. J Am Chem Soc. 1958; 80: 1339-1339. 10.1021/ja01539a017

Joosten RP. A series of PDB related databases for everyday needs. Nucleic Acids Res. 2011; 39: D411D419. 10.1093/nar/gkq1105

Kakaei K. High efficiency platinum nanoparticles based on carbon quantum dot and its application for oxygen reduction reaction. Int J Hydrogen Energy. 2017; 42: 11605-11613. 10.1016/j.ijhydene.2017.01.057

Kakaei K, Gharibi H. Palladium nanoparticle catalysts synthesis on graphene in sodium dodecyl sulfate for oxygen reduction reaction. Energy. 2014; 65: 166-171. 10.1016/j.energy.2013.12.005

Kakaei K, Rahimi A, Husseindoost S, Hamidi M, Javan H, Balavandi A. Fabrication of Pt-CeO2 nanoparticles supported sulfonated reduced graphene oxide as an efficient electrocatalyst for ethanol oxidation. Int J Hydrogen Energy. 2016; 41: 3861-3869. 10.1016/j.ijhydene.2016.01.013

Kakaei K, Esrafili MD, Ehsani A (2019) Chapter 9 - Graphene-based electrochemical supercapacitors. In: Kakaei K, Esrafili MD, Ehsani A (eds) Interface Science and Technology, vol 27. Elsevier, pp 339386. 10.1016/B978-0-12-814523-4.00009-5 
Kuretake T, Kawahara S, Motooka M, Uno S. An electrochemical gas biosensor based on enzymes immobilized on chromatography paper for ethanol vapor detection. Sensors (Basel). 2017; 17: 281. 10.3390/s17020281

Lacerda SHDP, Park JJ, Meuse C, Pristinski D, Becker ML, Karim A, Douglas JF. Interaction of gold nanoparticles with common human blood proteins. ACS nano. 2009; 4: 365-379. 10.1021/nn9011187

Malde AK. An automated force field topology builder (ATB) and repository: version 1.0. J Chem Theory Comput. 2011; 7: 4026-4037. 10.1021/ct200196m

Mofenson HC, Caraccio TR, Brody GM. Carbon monoxide poisoning. Am J Emergency Med. 1984; 2: 254-261. 10.1016/0735-6757(84)90016-0

Mojtaba $\mathrm{H}$, Ahmadvand $\mathrm{E}$, Ehsani A. Electroanalytical sensing of piperazine at carbon nanotubes/nafion composite-modified glassy carbon and screen-printed carbon electrodes in human plasma. J Anal Chem. 2020; 75: 238-245. 10.1134/S1061934820020069

Moosavi-Movahedi A. Micellar histidinate hematin complex as an artificial peroxidase enzyme model: Voltammetric and spectroscopic investigations. Colloids Surf A Physicochem Eng Asp. 2008; 320: 213-221. 10.1016/j.colsurfa.2008.01.047

Odom TW, Huang J-L, Kim P, Lieber CM. Atomic structure and electronic properties of single-walled carbon nanotubes. Nature. 1998; 391: 62-64. 10.1038/34145

Okamoto H, Obayashi H, Kudo T. Carbon monoxide gas sensor made of stabilized zirconia. Solid State Ionics. 1980; 1: 319-326. 10.1016/0167-2738(80)90012-0

Omidi M, Amoabediny G, Yazdian F, Habibi-Rezaei M. Hydrogen sul de detection using a gold nanoparticle/metalloprotein based probe. Chin Phys Lett. 2014; 31: 088701. 10.1088/0256307X/31/8/088701

Omidi M, Amoabediny G, Yazdian F, Habibi-Rezaei M. Protein-based nanobiosensor for direct detection of hydrogen sulfide EPL. Europhys Lett. 2015; 109: 18005. 10.1209/0295-5075/109/18005

Omidi M, Amoabediny G, Yazdian F, Habibi-Rezaei M. Protein based localized surface plasmon resonance gas sensing. Chin Phys Lett. 2015; 32: 018701. 10.1088/0256-307X/32/1/018701

Oostenbrink C, Soares TA, Van der Vegt NF, Van Gunsteren WF. Validation of the 53A6 GROMOS force field. Eur Biophys J. 2005; 34: 273-284. 10.1007/s00249-004-0448-6

Rashidi A et al Electromechanical properties of vertically aligned carbon nanotube. In: Advanced Materials Research, 2013. Trans Tech Publ, pp 332-336

Saito R, Fujita M, Dresselhaus G, Dresselhaus UM. Electronic structure of chiral graphene tubules. Appl Phys Lett. 1992; 60: 2204-2206. 10.1063/1.107080

Salehifar N, Shayeh JS, Ranaei Siadat SO, Niknam K, Ehsani A, Kazemi Movahhed S. Electrochemical study of supercapacitor performance of polypyrrole ternary nanocomposite electrode by fast Fourier transform continuous cyclic voltammetry. RSC Adv. 2015; 5: 96130-96137. 10.1039/C5RA18694C

Savage NO, Akbar SA, Dutta PK. Titanium dioxide based high temperature carbon monoxide selective sensor. Sensors Actuators B Chem. 2001; 72: 239-248. 10.1016/S0925-4005(00)00676-6

Sefidbakht Y, Nazari K, Farivar F, Moosavi-Movahedi Z, Sheibani N, Moosavi-Movahedi AA. Microperoxidase-11/NH2-FSM16 as a H2O2-resistant heterogeneous nanobiocatalyst: a suicideinactivation study. J Iran Chem Soc. 2012; 9: 121-128. 10.1007/s13738-011-0040-9

Sefidbakht Y, Ranaei Siadat O, Taheri F (2016) Homology modeling and molecular dynamics study on Schwanniomyces occidentalis alpha-amylase Journal of Biomolecular Structure and Dynamics:1-11 
Shayeh JS, Siadat SOR, Sadeghnia M, Niknam K, Rezaei M, Aghamohammadi N. Advanced studies of coupled conductive polymer/metal oxide nano wire composite as an efficient supercapacitor by common and fast fourier electrochemical methods. J Mol Liquids. 2016; 220: 489-494. 10.1016/j.molliq.2016.04.122

Siwko ME, Corni S. Cytochrome C on a gold surface: investigating structural relaxations and their role in protein-surface electron transfer by molecular dynamics simulations. Phys Chem Chem Phys. 2013; 15: 5945-5956. 10.1039/C3CP00146F

Soares CM, Martel PJ, Mendes J, Carrondo MA. Molecular dynamics simulation of cytochrome c3: studying the reduction processes using free energy calculations. Biophys J. 1998; 74: 17081721. 10.1016/S0006-3495(98)77882-8

Topoglidis E, Cass AE, Gilardi G, Sadeghi S, Beaumont N, Durrant JR. Protein adsorption on nanocrystalline TiO2 films: an immobilization strategy for bioanalytical devices. Anal Chem. 1998; 70: 5111-5113. 10.1021/ac980764l

Topoglidis E, Astuti Y, Duriaux F, Grätzel M, Durrant JR. Direct electrochemistry and nitric oxide interaction of heme proteins adsorbed on nanocrystalline tin oxide electrodes. Langmuir. 2003; 19: 6894-6900. 10.1021/la034466h

Wang L, Wang E. Direct electron transfer between cytochrome $\mathrm{c}$ and a gold nanoparticles modified electrode. Electrochem Commun. 2004; 6: 49-54. 10.1016/j.elecom.2003.10.004

Weaver LK. Carbon monoxide poisoning. Crit Care Clin. 1999; 15: 297-317. 10.1016/S07490704(05)70056-7

Wolf C, Xu H. Asymmetric catalysis with chiral oxazolidine ligands. Chem Commun. 2011; 47: 33393350. 10.1039/c0cc04629a

Zayasu K, Sekizawa K, Okinaga S, Yamaya M, Ohrui T, Sasaki H. Increased carbon monoxide in exhaled air of asthmatic patients. Am J Respir Crit Care Med. 1997; 156: 1140-1143. 10.1164/ajrccm.156.4.96-08056 